Supplement of The Cryosphere, 15, 2109-2114, 2021

https://doi.org/10.5194/tc-15-2109-2021-supplement

(c) Author(s) 2021. CC BY 4.0 License.

(c) (1)

Supplement of

\title{
Brief communication: New evidence further constraining Tibetan ice core chronologies to the Holocene
}

Shugui Hou et al.

Correspondence to: Shugui Hou (shugui@nju.edu.cn)

The copyright of individual parts of the supplement might differ from the article licence. 
- Figures S1 to S6.

- Tables S1 and S2. 


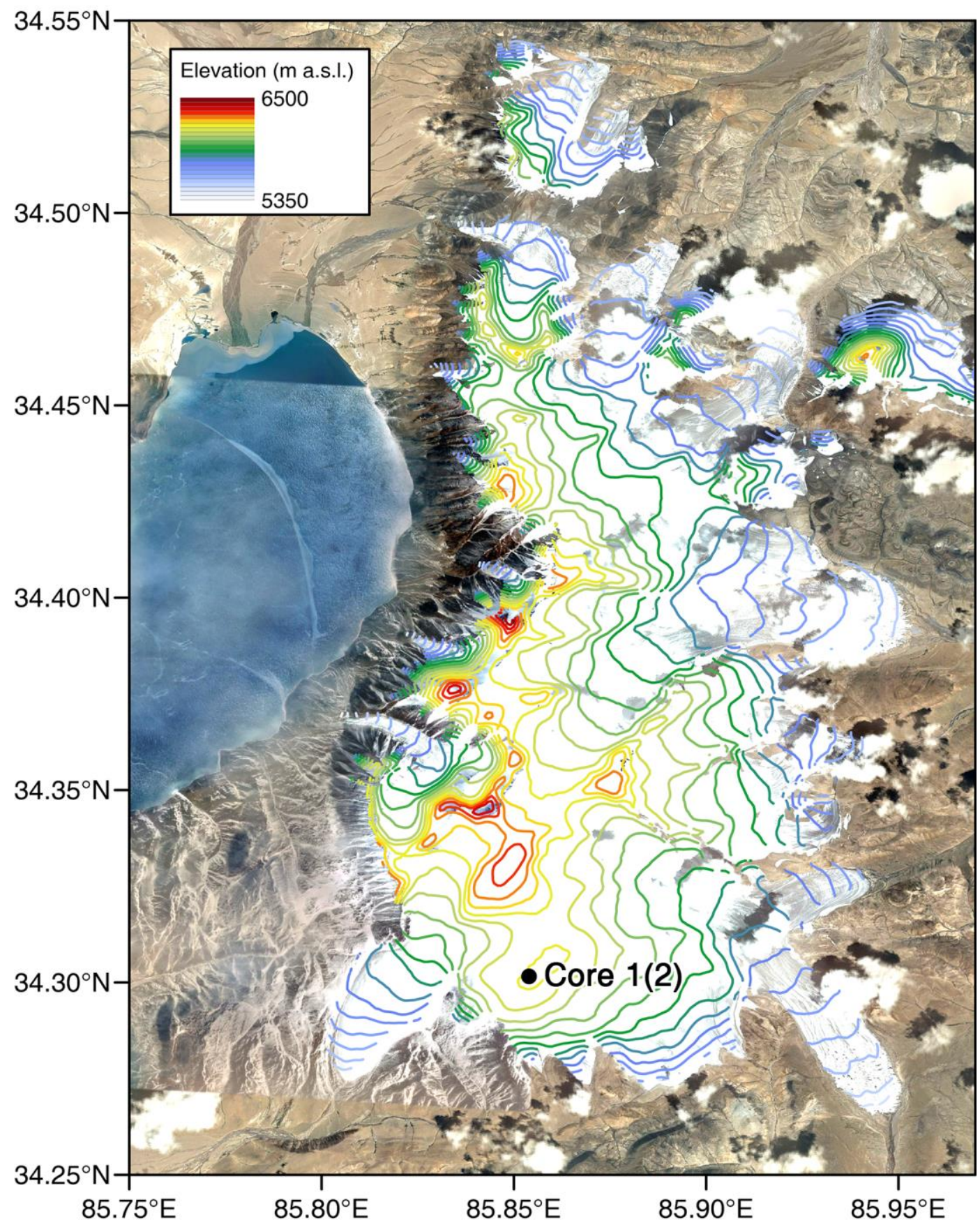

Fig. S1. (a) Satellite image of the ZK glacier with location of the ice-core drilling site

5 (black dot). Elevation contour lines were superimposed on the image of the ice cap.

The satellite imagery map is available at: https://www.mapsofworld.com/satellitemaps/world.html. The elevation contour data were extracted using the Shuttle Radar Topography Mission (SRTM) 90m DEM digital elevation database, available at http://srtm.csi.cgiar.org/. 

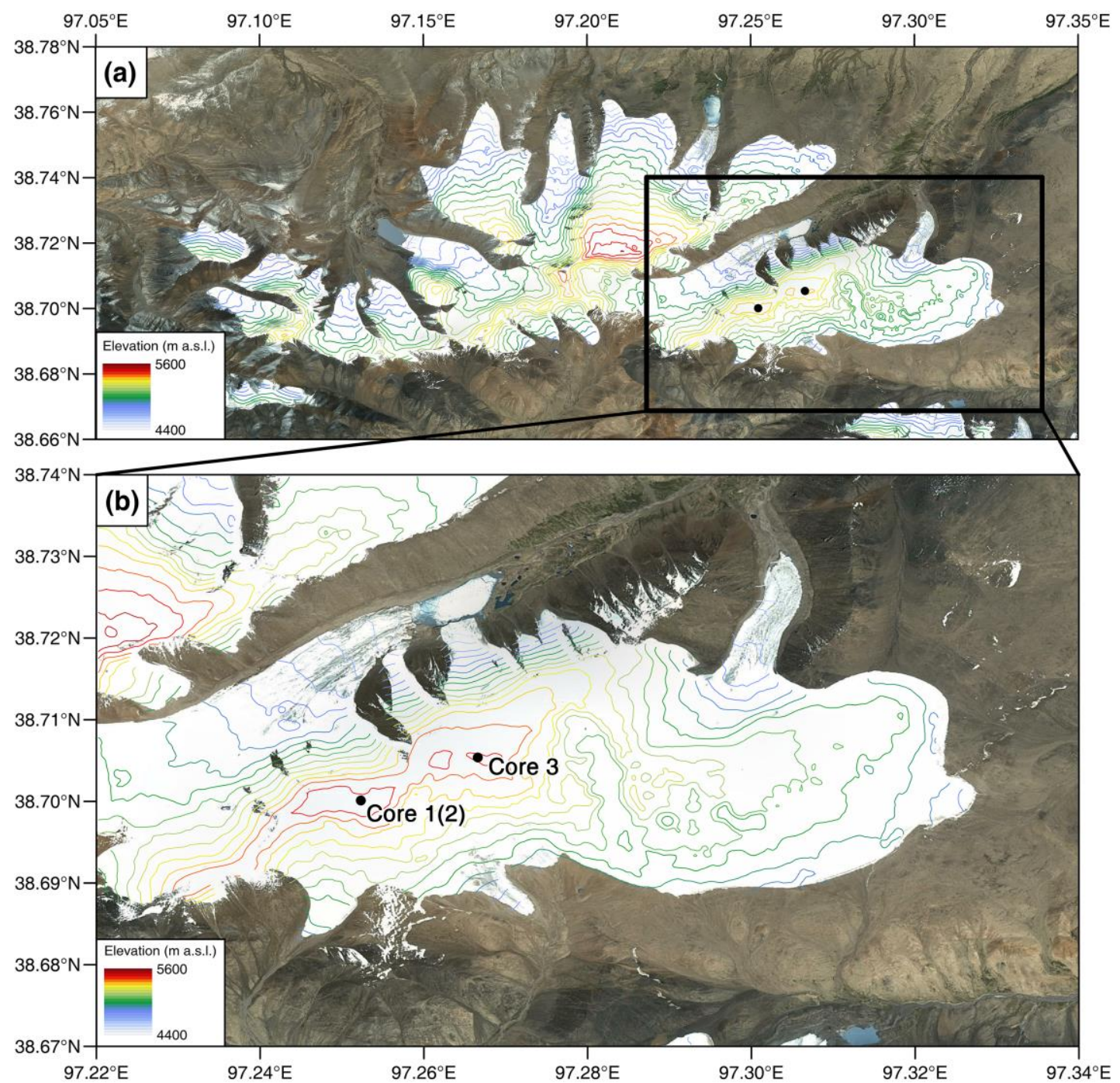

Fig. S2. Satellite image of the SLNS glacier with location of the ice-core drilling sites (black dots). Elevation contour lines were superimposed on the image of the glacier. The satellite imagery map is available at: https://www.mapsofworld.com/satellite15 maps/world.html. The elevation contour data were extracted using the Shuttle Radar Topography Mission (SRTM) 90m DEM digital elevation database, available at http://srtm.csi.cgiar.org/. 


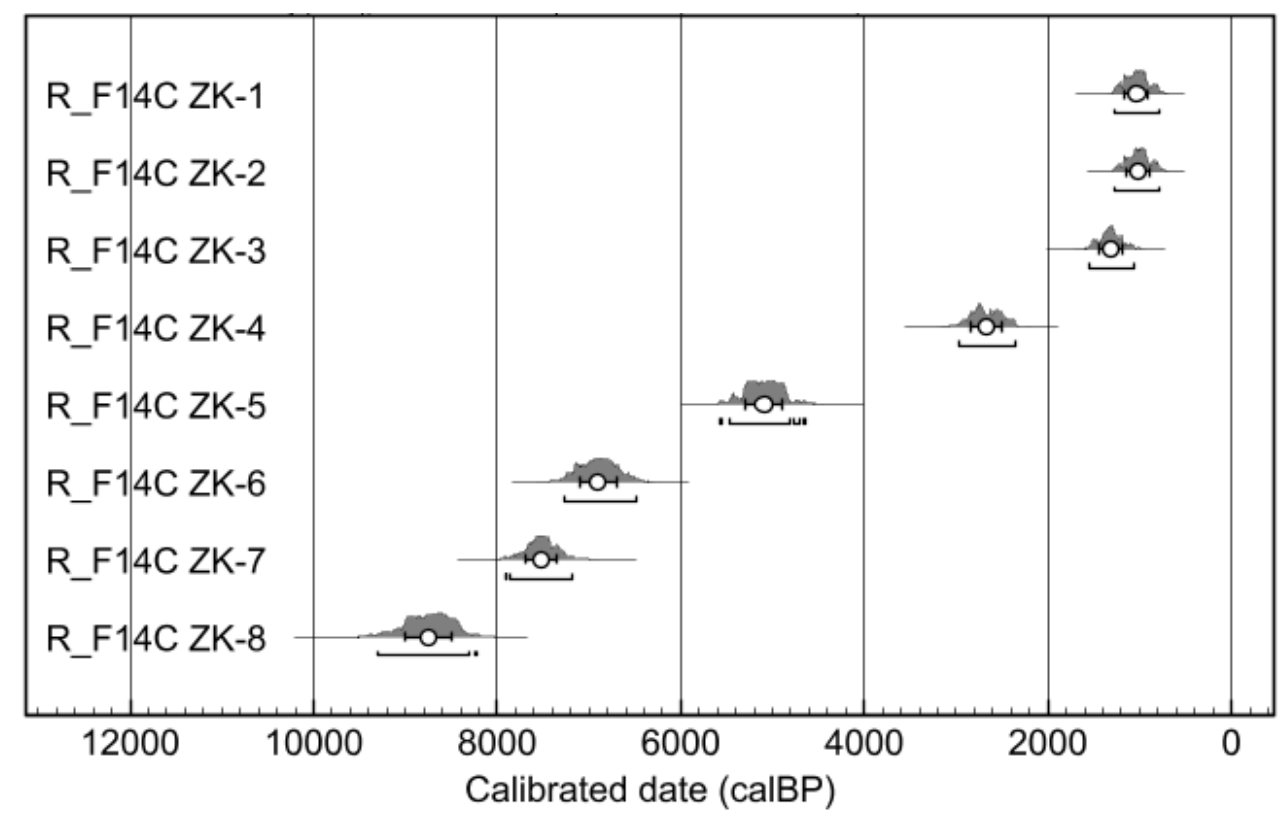

20 Fig. S3. The ${ }^{14} \mathrm{C}$ cal age probability distributions of the $\mathrm{ZK}$ ice core samples, as derived in OxCal v4.3.2 using the IntCal 13 radiocarbon calibration curve (Ramsey and Lee, 2013; Reimer et al., 2013). Probability distributions of calibrated ages are indicated as grey area with the mean age $(\mu)$ shown as dot together with the $1 \sigma$ range. The lines below the probability distribution areas indicate the $2 \sigma$ range. 

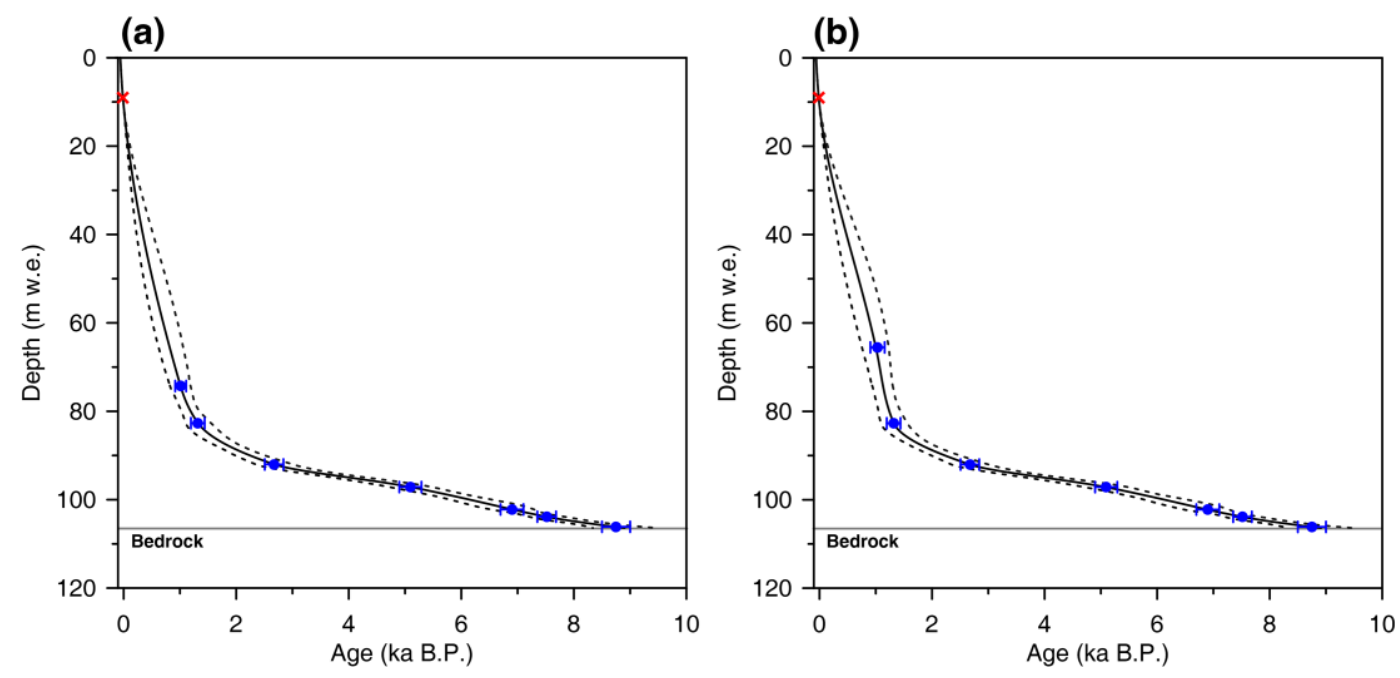

Fig. S4. The alternative age-depth relations of the ZK ice core derived without ZK-1 (a) or ZK-2 (b) based on 2000 Monte Carlo simulations fitting the absolute dated age horizons. For each chart, the solid black line indicates the mean values and dotted

30 lines indicate the $1 \sigma$ confidence interval. The red cross stands for the reference layer of $\beta$-activity peak in 1963 (An et al., 2016). Blue dots show the ages derived with the WIOC ${ }^{14} \mathrm{C}$ results, and the error bars represent the $1 \sigma$ range. The two models gave the bottom age estimates of $8.90 \pm_{0.57}^{0.56} \mathrm{ka} \mathrm{BP}$ (excluding ZK-1) or $8.91 \pm_{0.59}^{0.57} \mathrm{ka} \mathrm{BP}$ (excluding ZK-2) respectively. 


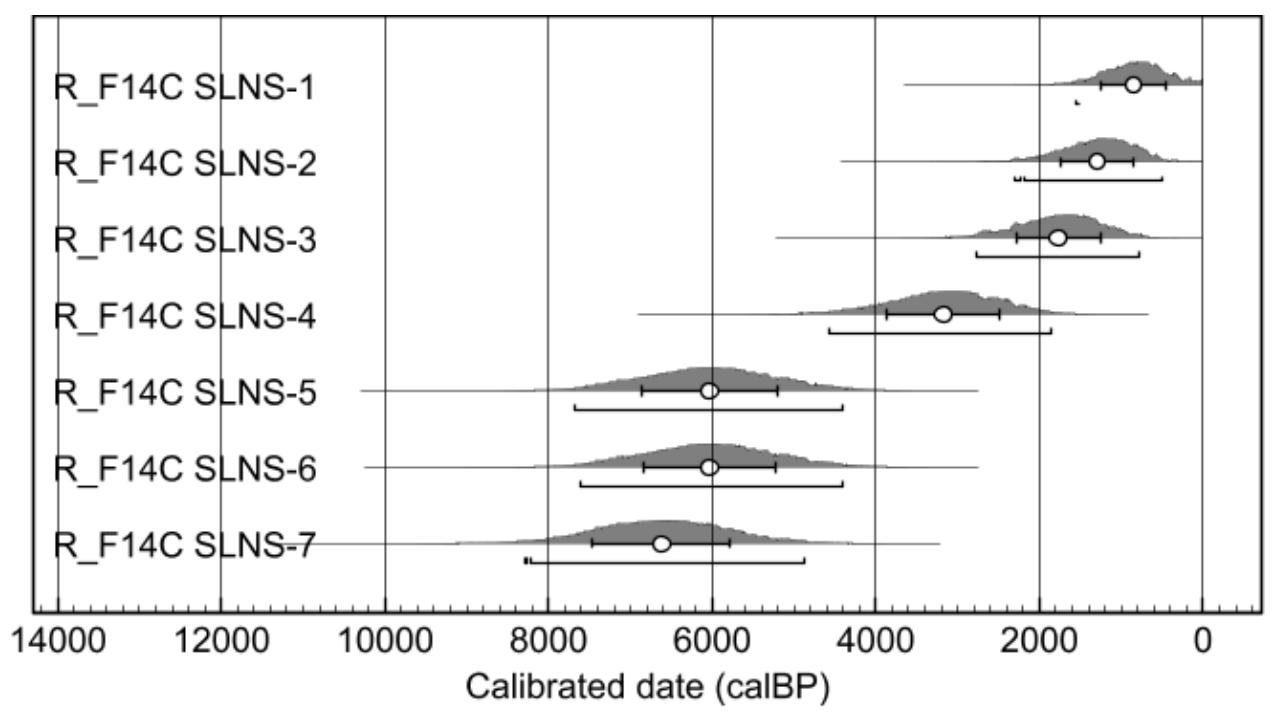

Fig. S5. The ${ }^{14} \mathrm{C}$ cal age probability distributions of the SNLS ice core samples, as derived in OxCal v4.3.2 using the IntCal 13 radiocarbon calibration curve (Ramsey and Lee, 2013; Reimer et al., 2013). Probability distributions of calibrated ages are

40 indicated as grey area with the mean age $(\mu)$ shown as dot together with the $1 \sigma$ range. The lines below the probability distribution area indicates the $2 \sigma$ range. 

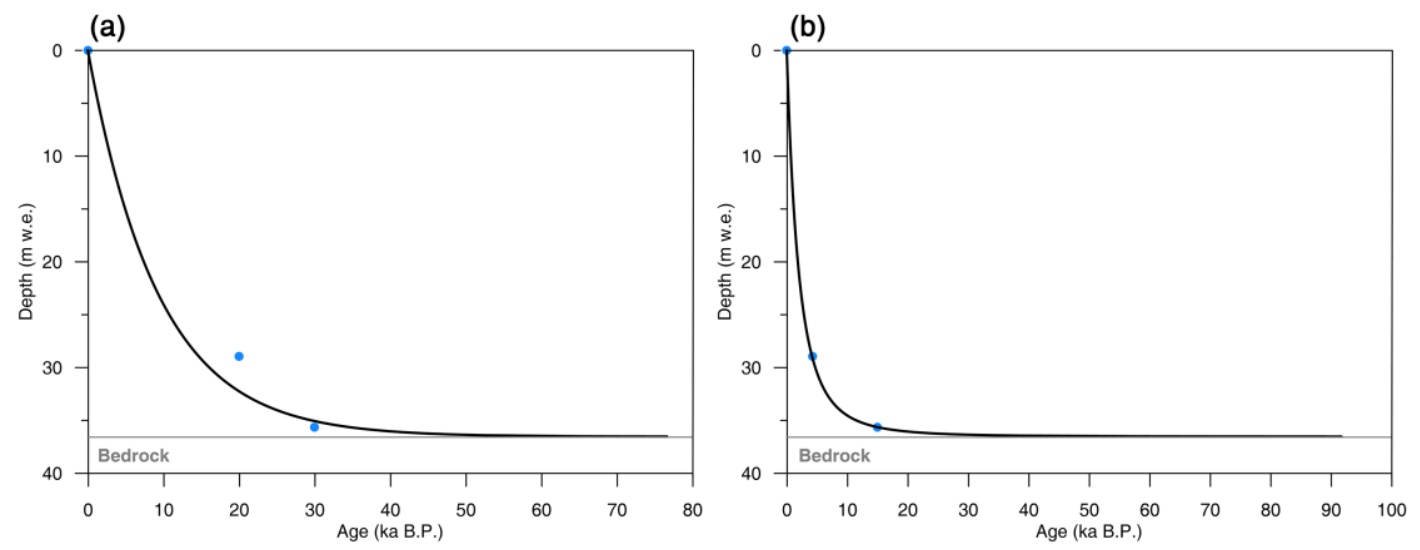

Fig. S6. The depth - age relationship of the $50.86 \mathrm{~m}$ Guliya2015 summit ice core based on the two ages at the depths of $41.10-41.84 \mathrm{~m}$ and $49.51-49.90 \mathrm{~m}$ from Zhong et al. (2018) (a) and revised ages from Zhong et al., 2020 (b) using a twoparameter (2p) flow model. Confidence interval of the $2 p$ model fit cannot be calculated due to a lack of data. More details about the model can be found in Hou et al. (2019). 
50 Table S1. The ${ }^{14} \mathrm{C}$ ages of the $127.776 \mathrm{~m} \mathrm{ZK}$ ice core. Absolute uncertainties are given as $1 \sigma$ range.

\begin{tabular}{|c|c|c|c|c|c|c|c|c|}
\hline Sample \# & Depth (m) & Mass (g) & $\begin{array}{c}\text { WIOC } \\
(\mu \mathrm{g})\end{array}$ & $\begin{array}{c}\text { Bern AMS } \\
\text { No. }\end{array}$ & $\mathrm{F}^{14} \mathrm{C}$ & $\begin{array}{l}{ }^{14} \mathrm{C} \text { age } \\
(\mathrm{ka} \mathrm{BP})\end{array}$ & $\begin{array}{c}\text { Cal age } \\
\text { (ka cal BP) }\end{array}$ & $\begin{array}{c}\mu \pm \sigma \\
(\mathrm{ka} \mathrm{cal} \mathrm{BP})\end{array}$ \\
\hline ZK-1 & $79.96-80.92$ & 940 & 50 & 10075.1 .1 & $0.872 \pm 0.013$ & $1.100 \pm 0.118$ & $0.923-1.178$ & $1.031 \pm 0.127$ \\
\hline ZK-2 & $89.98-90.68$ & 588 & 130 & 10084.1 .1 & $0.874 \pm 0.012$ & $1.079 \pm 0.110$ & $0.917-1.174$ & $1.013 \pm 0.123$ \\
\hline ZK-3 & $99.89-100.59$ & 566 & 55 & 10091.1.1 & $0.840 \pm 0.012$ & $1.398 \pm 0.115$ & $1.181-1.475$ & $1.317 \pm 0.122$ \\
\hline ZK-4 & $110.77-111.39$ & 590 & 60 & 10093.1.1 & $0.723 \pm 0.011$ & $2.610 \pm 0.125$ & $2.491-2.854$ & $2.673 \pm 0.166$ \\
\hline ZK-5 & $116.58-117.33$ & 852 & 128 & 10094.1.1 & $0.575 \pm 0.010$ & $4.446 \pm 0.146$ & $4.879-5.286$ & $5.095 \pm 0.197$ \\
\hline ZK-6 & $122.57-123.27$ & 614 & 89 & 10095.1.1 & $0.475 \pm 0.010$ & $6.033 \pm 0.168$ & $6.634-7.154$ & $6.901 \pm 0.204$ \\
\hline ZK-7 & $124.54-125.15$ & 548 & 200 & 10096.1.1 & $0.438 \pm 0.010$ & $6.637 \pm 0.182$ & $7.329-7.674$ & $7.517 \pm 0.166$ \\
\hline ZK-8 & $127.18-127.78$ & 558 & 113 & 10027.1 .1 & $0.376 \pm 0.009$ & $7.863 \pm 0.205$ & $8.481-8.983$ & $8.750 \pm 0.250$ \\
\hline
\end{tabular}


Table S2. The ${ }^{14} \mathrm{C}$ age of the $81.05 \mathrm{~m}$ SLNS ice core. Absolute uncertainties are given as $1 \sigma$ range.

\begin{tabular}{|c|c|c|c|c|c|c|c|c|}
\hline $\begin{array}{c}\text { Sample } \\
\#\end{array}$ & Depth (m) & $\begin{array}{l}\text { Mass } \\
\text { (g) }\end{array}$ & $\begin{array}{c}\text { WIOC } \\
(\mu \mathrm{g})\end{array}$ & $\begin{array}{c}\text { Bern AMS } \\
\text { No. }\end{array}$ & $\mathrm{F}^{14} \mathrm{C}$ & $\begin{array}{l}{ }^{14} \mathrm{C} \text { age } \\
(\mathrm{ka} \mathrm{BP})\end{array}$ & $\begin{array}{c}\text { Cal. age } \\
\text { (ka cal BP) }\end{array}$ & $\begin{array}{c}\mu \pm \sigma \\
(\mathrm{ka} \mathrm{cal} \mathrm{BP})\end{array}$ \\
\hline $\begin{array}{l}\text { SLNS-1 } \\
\end{array}$ & 56.79-57.49 & 420 & 42 & 12325.1 .1 & $0.902 \pm 0.047$ & $0.829 \pm 0.419$ & $0.492-1.262$ & $0.851 \pm 0.395$ \\
\hline SLNS-2 & $64.66-65.36$ & 426 & 45 & 12324.1 .1 & $0.852 \pm 0.046$ & $1.287 \pm 0.434$ & $0.766-1.688$ & $1.298 \pm 0.449$ \\
\hline SLNS-3 & $68.88-69.69$ & 425 & 59 & 12323.1 .1 & $0.807 \pm 0.046$ & $1.723 \pm 0.458$ & $1.185-2.301$ & $1.775 \pm 0.514$ \\
\hline SLNS-4 & $71.84-72.50$ & 483 & 51 & 12322.1 .1 & $0.695 \pm 0.046$ & $2.923 \pm 0.531$ & $2.365-3.708$ & $3.178 \pm 0.680$ \\
\hline SLNS-5 & $76.75-77.46$ & 374 & 51 & 12321.1 .1 & $0.522 \pm 0.046$ & $5.222 \pm 0.708$ & $5.071-6.881$ & $6.033 \pm 0.829$ \\
\hline SLNS-6 & $78.90-79.63$ & 485 & 61 & 12320.1 .1 & $0.522 \pm 0.045$ & $5.222 \pm 0.692$ & $5.075-6.854$ & $6.032 \pm 0.811$ \\
\hline SLNS-7 & $80.30-81.02$ & 413 & 62 & 12319.1.1 & $0.489 \pm 0.046$ & $5.747 \pm 0.740$ & $5.761-7.424$ & $6.619 \pm 0.841$ \\
\hline
\end{tabular}

